\title{
A DESIGN CRITERIA OF BEAM-TO-COLUMN JOINT PANELS
}

\author{
B. Kato*
}

\begin{abstract}
The performance of beam-to-column joint panels of steel frames under horizontal loading is surveyed in elastic and plastic regions. Then the influence of shear deformation of those joint panels on the frame stiffness is investigated. It is found that the frame stiffness reduces remarkably when the yielding of joint panels takes place. Taking into account these observations, a simple and practical design method of various shapes of joint panels is suggested.
\end{abstract}

\section{INTRODUCTION}

When a steel frame is subjected to horizontal force due to earthquake or wind turbulence, high shears are developed in the beam-to-column joint panels, which may cause premature yielding and local distortion of them and thus may reduce the frame stiffness.

Though this fact had been recognised rather earlier (1), it is in this decade that a number of full scale tests were carried out to determine the strength and deformation of those joint panels (2), (3), (4), (5). Limit analysis of joint panels (6), research on the behaviour of joint panels under cyclic loading (7), (8), and that of the influence of shear deformation of joint panels on the sway behaviour of frames (9), (10), (11), were also carried out.

The writer attempts to assess the role of those panel behaviours and to predict a simple and useful interpretation of available data.

\section{BEHAVIOUR OF JOINT PANEL}

\subsection{Elastic Behaviour}

When a rigid frame is subjected to horizontal force as well as gravity load, the stress diagram at the vicinity of a beam-to-column joint can be depicted as shown in Fig. 1 (a). At first, beams and columns are assumed to be composed of $\mathrm{H}-$ shape sections. Referring to Fig. 1 (b), the equilibrium of these forces about the center of joint panel is

$$
\begin{gathered}
-M_{b 1}-Q_{b 1} \frac{h_{c}}{2}-M_{b 2}-Q_{b 2} \frac{h_{c}}{2}+M_{c l} \\
+Q_{c l} \frac{h_{b}}{2}+M_{c 2}+Q_{c 2} \frac{h_{b}}{2}=0
\end{gathered}
$$

where $h_{b}=$ distance between centers of beam flanges $\mathrm{h}_{\mathrm{c}}=\underset{\text { distance between centers of column }}{\text { flanges }}$

* Professor of Structural Engineering, University of Tokyo, Tokyo, Japan.

$$
t_{w}=\begin{aligned}
& \text { thickness of panel plate (thick- } \\
& \text { ness of column web) }
\end{aligned}
$$

It is convenient to break down this loading system into "horizontal load type" and "gravity load type", as illustrated in Fig. 2. Any set boundary forces on a joint panel may be replaced by an equivalent system consisting of these forces.

$$
\begin{aligned}
& M_{b 1}+\frac{M_{b 1}+M_{b 2}}{2}+\frac{M_{b 1}-M_{b 2}}{2}=h^{M_{b}}+v^{M_{b}} \\
& M_{b 2}=\frac{M_{b 1}+M_{b 2}}{2}-\frac{M_{b 1}-M_{b 2}}{2}=h^{M_{b}}-v^{M_{b}} \\
& M_{C l}=\frac{M_{C l}+M_{C 2}}{2}+\frac{M_{C l}-M_{c 2}}{2}=h^{M_{c}}+v^{M_{C}} \\
& M_{C 2}=\frac{M_{C l}+M_{C 2}}{2}-\frac{M_{C l}-M_{c 2}}{2}=h^{M_{c}}{ } \cdot v^{M} \\
& Q_{b 1}=\frac{Q_{b 1}+Q_{b 2}}{2}+\frac{Q_{b 1}-Q_{b 2}}{2}={ }_{h} Q_{b}+v_{b} \\
& Q_{b 2}=\frac{Q_{b 1}+Q_{b 2}}{2}-\frac{Q_{b l}-Q_{b 2}}{2}=h^{Q_{b}}-v^{Q_{b}} \\
& Q_{c l}=\frac{Q_{c l}+Q_{C 2}}{2}+\frac{Q_{c l}-Q_{c 2}}{2}=h_{c}+v^{Q_{C}} \\
& Q_{c 2}=\frac{Q_{c 1}+Q_{c 2}}{2}-\frac{Q_{c 1}-Q_{c 2}}{2}=h^{Q_{c}}-v^{Q_{c}} \\
& \mathrm{~N}_{1}=\frac{\mathrm{N}_{1}+\mathrm{N}_{2}}{2}+\frac{\mathrm{N}_{1}-\mathrm{N}_{2}}{2}=\mathrm{h}^{\mathrm{N}}+\mathrm{v}^{\mathrm{N}} \\
& \mathrm{N}_{2}=\frac{\mathrm{N}_{1}+\mathrm{N}_{2}}{2}-\frac{\mathrm{N}_{1}-\mathrm{N}_{2}}{2}=\mathrm{h}^{\mathrm{N}}-\mathrm{v}^{\mathrm{N}}
\end{aligned}
$$

Now. eq. 1 can be simplified to read;

$$
2 h^{M_{b}}-h^{Q_{c}} h_{b}=2 h^{M} c-h^{Q_{b}} h_{c}
$$

The main problems relating to the "gravity load type" are 1) local deformation in relation to the efficiency of the connections and 2) local buckling, of which enough information has been obtained (12). On the other hand, for the "horizontal load type", the distortion caused by shear stress is especially important. Eq. (2) can be 
rearranged as

$$
\begin{gathered}
\frac{1}{h_{c} t_{w}}\left(\frac{M_{b l}+M_{b 2}}{h_{b}}-\frac{Q_{c l}+Q_{c 2}}{2}\right)= \\
\frac{1}{h_{b} t_{w}}\left(\frac{M_{c l}+M_{c 2}}{h_{c}}-\frac{Q_{b l}+Q_{b 2}}{2}\right)
\end{gathered}
$$

The first term in the parenthesis of the right side of eq. (3) is the equivalent couple force $F$ acting on the beam flange levels as shown in Fig. 2, and then the total terms in the parenthesis mean the horizontal shear force acting on the joint panel. Average shear stress in joint panel is obtained by dividing this by $h_{c} t_{w}$. Similarly, the left side of eq. (3) is the average vertical shear stress in the joint panel. Hence, eq. (3) can be regarded as expressing the equilibrium of shear stress in the joint panel. Then an approximate yield criterion of the joint panel can be written as

$$
\begin{aligned}
& \bar{\tau}=\frac{M_{b l}+M_{b 2}}{h_{b} h_{c} t_{w}}-\frac{Q_{c l}+Q_{c 2}}{2 h_{c} t_{w}} \leq \tau_{y} \\
& \bar{\gamma}=\frac{\tau}{\tau} / G
\end{aligned}
$$

where $\tau_{y}=1 / \sqrt{3} \sigma_{y}: \begin{aligned} & \text { yield shear stress of } \\ & \text { panel material }\end{aligned}$

$$
G=\frac{E}{2(1+U)} \text { : elastic shear modulus }
$$

In the foregoing description, it was assumed that most of the bending moment and axial thrust of the column were carried by the flanges. Then the following limitation should be made to satisfy this assumption,

$$
\frac{\mathrm{M}_{\mathrm{Cl}}}{\mathrm{h}_{\mathrm{C}}}+\frac{\mathrm{N}_{\mathrm{cl}}}{2} \leq \mathrm{A}_{\mathrm{f}} \sigma_{\mathrm{Y}}
$$
where $A_{f}=\begin{aligned} & \text { sectional area of a flange of } \\ & \text { the column }\end{aligned}$

Most of the test results, had shown much higher resistance than was predicted by eq. (5) without substantial reduction of the stiffness, perhaps due to the favourable effect of strain-hardening. It was reported, however, that the effect of axial compression of the column can not be ignored when the magnitude of it is unusually large (8). Residual stresses will also affect the initiation of the yielding of a joint panel. In joint panels, locked in stress and residual stress due to welding assembly may be induced in addition to the thermal residual stress inherent to the rolled and welded steel sections as well. Consequently, the initiation of yielding may be scattered depending on the fabricating conditions. Though accurate stress distribution in a joint panel was obtained on the basis of theory of elasticity (7), having been disturbed by those residual stresses, this theoretical prediction could not explain the test result very well.

\subsection{Inelastic Behaviour}

Fig. 3 shows the elastic-plastic behaviour of joint panels obtained from experiments (13), where $\bar{\tau}$ is the average shear stress and $\bar{\gamma}$ is the average shear deformation of a joint panel. The significant features observed from those curves are:

1). As yielding spreads throughout the joint panel, a sharply defined knee is observed.

2). Beyond the knee the response is approximately linear again, and the ductility is very large, usually more than 20 times the yield shear deformation $\bar{\gamma}_{y}$. As far as experimental evidence had revealed, premature shear buckling of the joint panel will be unlikely to occur provided that a joint panel is proportioned to satisfy the formula which will be proposed later.

3). The slope in plastic region varies from three to eight per cent of the elastic slope. An average value of five per cent may be an optimum for the practical use. In reference 11 , this plastic slope was evaluated analytically.

\section{INFLUENCE OF SHEAR DEFORMATION OF JOINT}

In conventional analyses of frames subjected to horizontal force, it is usually assumed that: 1) the connections are rigid or 2) the sizes of the connections are negligible so that frames are represented by member center lines and joints are treated as rigidly connected intersections of such center lines. Recently, the effect of shear deformation of joint panels as well as that of members on the behaviour of frames subjected to horizontal force was investigated by several researchers (9), (10), (11).

Herein, a five-story two bay steel frame subjected to horizontal force is analysed. Comparative studies are made among frame behaviours on the assumptions of 1) the connections are rigid, 2) the sizes of the connections are negligible and 3) the effect of shear deformation of joint panels is considered. Where bi-linear type of $\bar{\tau}-\bar{\gamma}$ relation is assumed, elastic behaviour is given by eq. (4) and in the plastic region, the stiffness is reduced to five per cent of that of elastic region as mentioned earlier. Dimensions of this sample frame are shown in Fig. 4, drift curves of the lst story and $3 r d$ story respectively. From these figures, the following can be observed:

-- In the elastic region, the solution based on the assumption 2) gives a good approximation to the exact solution based on the assumption 3). Assumption 2) results in greater member lengths than actual ones and thus reduces the frame stiffness. This will compensate the exror caused by the assumption of rigid panel point.

-- In the plastic region, the difference of behaviours between those based on assumption 2) and assumption 3) becomes remarkable. Side sway of the frame becomes too large to be tolerated even in the case of severe earthquake, when the yielding of joint panels has taken place. 


\section{DESIGN CRITERION OF JOINT PANELS}

It was seen, in the previous chapter, that the stiffness of a trame will be reduced remarkably and thus the side sway of it will become very large, when the yielding of joint panels has taken place. Excessive side sway of a frame is a cause of overall instability due to the effect of $P-\Delta$ moment, and furthermore, the excessive shear deformation of a joint panel due to yielding will induce the local buckling of adjacent beams and columns. Hence, it would be a safe side criterion to ensure that the substantial yielding of joint panels should not be allowed even when a frame be subjected to severe earthquake force and plastic deformation of the frame as a whole will take place. By doing so, as was seen in the previous chapter, the conventional frame analysis to employ center line dimensions can give a good prediction of actual frame behaviour (see Fig. 5, Fig. 6). As an adaitional advantage, this makes the frame analysis very simple.

For the strong earthquake, however, under which beams and columns of a frame undergo plastic deformation, it is difficult to design joint panels to remain in the elastic state in the rigorous sense unless they are heavily reinforced. Herein, the criterion is that though partial yielding in the panels and thus slight reduction of stiffness may be tolerated, the virtual yielding (plastic flow) should be prevented. The following comments, most of which have been mentioned already in the foregoing chapters, may back up the choice of this criterion.

-- the uitimate strength of joint panels is much higher than that predicted by simple plastic theory due to the effect of strain-hardening.

-- the behaviour of joint panels is very ductile, unlikely to undergo premature failure such as local buckling. This may provide a potential capacity of joint panels. (see Fig. 3).

-.- when a joint panel is subjected to cyclic loading, the hysteresis loop expands for every additional cycle as seen in Fig. 7 (7). This causes an apparent increase of resisting capacity of the panel.

-. Due to the existence of residual stress in complicated distribution, exact prediction of the initiation of yielding becomes almost impossible (7).

\section{I H-Shape Column (Fig. 8)}

Modifying eq. (4), the next simplified design formula is proposed.

$$
\begin{aligned}
& \bar{\tau}=\frac{M_{b 1}+M_{b 2}}{V_{p}} \leq 0.77 \sigma_{\mathrm{Y}} \\
& \bar{\gamma}=\bar{\tau} / G
\end{aligned}
$$

where $V_{p}=$ effective shear volume and is equal to $h_{b} h_{c} t_{w}$ for $H$-shape column $\sigma_{y}=$ yield point of materials (web plate of $\mathrm{H}$-column)

The term pertaining to column shear force $\frac{Q_{C 1}+Q_{C 2}}{2 h_{C} t_{W}}$ in eq. (4) is neglected in above

formula. This leads to overestimating the external shear acting on the joint panel. To compensate for this, the critical shear stress is multiplied by $4 / 3$, namely

$$
\frac{4}{3} \tau_{y}=\frac{1}{3 \sqrt{3}} \sigma_{y}=0.77 \sigma_{y}
$$

This multiple is decided by engineering judgement on the basis of experimental results. In Fig. 9, a test result (14) is compared with the prediction of eq. (6). In eq. (6), it is recommended that $h_{b}, h_{c}$ should be measured as the distances between inner faces of diaphragms and column flanges respectively as shown in Fig. 8 .

In the following, appropriate expressions for the effective shear volume $V_{p}$ are sought for different shape of joint panels applicable to eq. (6).

\subsection{Box Shape Column}

In Fig. 10, the shaded area, that of plate elements parallel to the bending plane, is assumed to be effective against the shear. The couple force $F$ is

$$
F=\frac{M_{b 1}+M_{b 2}}{h_{b}}
$$

Average shear $\bar{\tau}$ is

$$
\bar{\tau}=\frac{F}{2 h_{c} t_{w}}=\frac{M_{b l}+M_{b 2}}{2 h_{b} h_{c} t_{w}}
$$

Thus the effective shear volume $V_{p}$ is

$$
v_{p}=2 h_{b} h_{c} t_{w}
$$

In case of square box section with equal wall thickness,

$$
\mathrm{v}_{\mathrm{p}}=1 / 2 \mathrm{~V}
$$

were $V$ is the total volume of connection part surrounded by beam and column ends.

A test result (15) is compared with the prediction obtained from eqs. (6) and (7) in Fig. 11 .

\subsection{Tubular Column (Fig. 12)}

The couple force $F$ is

$$
F=\frac{M_{b 1}+M_{b 2}}{h_{b}}
$$

Shear distribution of a circular tube is

$$
\tau_{u}=\frac{2 F}{A} \sin \alpha
$$

Maximum shear occurs at $\alpha=\pi / 2$ and

$$
\tau_{\max }=\frac{2 F}{A}
$$


where $\mathrm{A}=$ sectional area of a tube.

It will be a little conservative but a fair assumption that yielding will take place when $\tau_{\max }$ at $\alpha=\pi / 2$ attains yield point, and thex,

$$
\tau_{\max }=\frac{M_{b 1}+M_{b 2}}{1 / 2 h_{b} A} \leqq 0.77 \sigma_{y}
$$

Thus

$$
\mathrm{V}_{\mathrm{p}}=1 / 2 \mathrm{~V}
$$

Comparison between a test result (15) and the prediction from eqs. (6) and (8) is given in Fig. 13.

\subsection{Cross H Shape Column}

The shaded parts in Fig. 14 are assumed to be effective for shear resistance

$$
F=F_{W}+2 F_{f}
$$

$$
\text { where } \begin{aligned}
F_{w}= & \text { shear force resisted by the } \\
& \text { web plate of } \mathrm{H}-\mathrm{shape} \text { in the } \\
& \text { plane of bending }
\end{aligned}
$$

Shear deformation will dominate in the element $\mathrm{H}_{1}$ of $\mathrm{Fig} .14$ as the flexural rigidity is very large. On the contrary, for flanges of the element $\mathrm{H}_{2}$ of Fig. 14 both deformations due to shear and bending must be considered as the flexural rigidity of each flange is relatively. small. For simplicity, those flanges are assumed to be supported rigidly at the levels of the diaphragm. The compatibility of sway displacement of both elements is

$$
\frac{F_{f}}{A_{f} G} h_{b}+\frac{F_{f}}{12 E I_{f}} h_{b}^{3}=\frac{F_{w}}{A_{w} G^{b}}
$$

where $A_{f}=b t_{f}=$ sectional area of each

$$
\begin{aligned}
A_{w}= & h_{c} t_{w}=\text { sectional area of web } \\
I_{f}= & \text { moment of inertia of each } \\
& \text { flange plate with respect of its } \\
& \text { strong axis }
\end{aligned}
$$

This can be reduced to

$$
\begin{aligned}
& F_{f}=\frac{2(1-\nu) B}{\alpha^{2}+2(1+\nu)} F_{w}, \alpha=\frac{h_{b}}{b}, \\
& B=\frac{A_{f}}{A_{W}}
\end{aligned}
$$

From eqs. (9) and (10).

$$
F=\frac{\alpha^{2}+2(1+\nu)(1+2 \beta)}{\alpha^{2}+2(1+\nu)} F_{w}
$$

Commonly flanges yield first, but this does not affect the overall stiffness of the joint panel so much as the shear capacity of those flanges is relatively small. Hence, the substantial yielding of the joint panel is assumed to occur when the yielding of web plate takes place finally. This situation is illustrated schematically in Fig. 15. Then the yield strength of this joint panel can be obtained by introducing $\left(F_{w}\right)_{y}=h_{c} t_{w} \tau_{y}$ into eq. (11). Furthermore, for practical design formula $\tau_{y}$ can be replaced by $0.77 \sigma_{y}$ as was previously mentioned. Thus finally,

$$
F=\frac{M_{b l}+M_{b 2}}{h_{b}} \leq \frac{\alpha^{2}+2(1+v)(1+2 \beta)}{\alpha^{2}+2(1+v)} 0.77 \sigma_{y} h_{c} t_{w}
$$

or

$$
\frac{\mathrm{M}_{\mathrm{bl}}+\mathrm{M}_{\mathrm{b} 2}}{\phi \mathrm{V}_{\mathrm{w}}} \leq 0.77 \sigma_{\mathrm{y}}
$$

where $v_{w}=h_{b} h_{c} t_{w}=$ volume of web plate parallel to the bending plane in the panel zone

$$
\begin{aligned}
& \phi=\frac{\alpha^{2}+2.6(1+2 \beta)}{\alpha^{2}+2.6}, \alpha=\frac{h_{b}}{b}, \\
& \beta=\frac{A_{f}}{A_{W}}, \quad(\nu=.03 \text { is assumed })
\end{aligned}
$$

Eq. (12) means that the effective shear volume in this case is $\mathrm{V}_{\mathrm{p}}=\phi \mathrm{V}_{\mathrm{w}}$. Comparison between a test result (15) and the prediction obtained from eq. (12) is given in Fig. 16.

\section{SUGGESTED DESIGN METHOD}

5.1 A design criterion to prevent excessive shear deformation of joint panels when a frame is subjected to horizontal loading such as earthquake and wind is proposed.

This criterion is applicable to the steel frames which satisfy following conditions :

a) a joint panel has the same sectional shape as that of joining columns.

b) a joint panel is stiffened by a pair of diaphragms located at the levels of beam flanges to be connected.

c) axial compression of the column is not unusually large.

5.2 The condition which a joint panel should satisfy is

$$
\bar{\tau}=\frac{\mathrm{M}_{\mathrm{bl}}+\mathrm{M}_{\mathrm{b} 2}}{\mathrm{~V}_{\mathrm{p}}} \leq 0.77 \sigma_{\mathrm{y}}
$$

Average shear deformation of a joint panel $\bar{\gamma}$ is

$$
\bar{\gamma}=\bar{\tau} / G
$$

5.3 Effective shear volume $v_{p}$

a) H shape column

$$
\begin{aligned}
& v_{p}=h_{b} h_{c} t_{w} \\
& --h_{b}, h_{c} \text { should be measured as the }
\end{aligned}
$$


distances between inner faces of diaphragms and column flanges respectively.

b) Box shape column

$$
v_{p}=2 h_{b} h_{c} t_{w}
$$

- - $h_{b}, h_{c}$ can be measured as the distances between center lines of the thickness of diaphragms and column flanges respectively.

-- in case of square box section with equal wall thickness

$$
v_{p}=1 / 2 \mathrm{~V}
$$

where $\mathrm{V}$ is the total volume of connection part surrounded by beam and column ends.

C) Tubular column

$$
\mathrm{v}_{\mathrm{p}}=1 / 2 \mathrm{~V}
$$

d) Cross-H shape column

$$
\begin{gathered}
V_{p}=\phi V_{W} \\
\text { where } \phi=\frac{\alpha^{2}+2.6(1+2 B)}{\alpha^{2}+2.6}, \alpha=\frac{h_{b}}{b}, \\
B=\frac{A_{f}}{A_{W}} \\
V_{W}=h_{b} h_{C} t_{W}=\begin{array}{l}
\text { volume of web plate } \\
\text { parallel to the bending } \\
\text { plane in the panel zone. }
\end{array}
\end{gathered}
$$

\section{REFERENCES}

(1) Naka, T. et al, Load Carrying Capacity of Steel Rigid Frame (No. 4), Regional Congress of Kanto Branch, Architectural Institute of Japan, September, 1954. (in Japanese)

(2) Naka, T., Kato, B., and Watabe, M. Research on the Behaviour of Steel Beam-to-Column Connections. Laboratory for Steel Structures, Dept. of Architecture, University of Tokyo, Japan, 1966.

(3) Krawinkler, H., Bertero, V. V., and Popov, E. P., Behaviour of Steel BeamColumn Subassemblages Under Cyclic Loading, Progress Report to American Iron and Steel Institute Project 145, University of California at Berkeley. Calif. "Feb. 1970 .

(4) Nakao, M., et al. Reinforcing Effect of Beam-to-Column Joint Panels, Annual Meeting of Architectural Institute of Japan, september, 1970. (in Japanese)

(5) Fielding, D., and Huang, J. S., Shear in Steel Beam-to-Column Connections, Welding Journal, Vol. 50, No. 7 , Research Supplement, 1971.

(6) Tanaka, H., and et al., Limit Analysis of Beam-to-Column Connections, Trans. of Architectural Institute of Japan, 1968 through 1971.

(7) Naka, T., et al., Behaviour of Beam-toColumn Joint Panels Subjected to Horizontal Loads (No. 3), Trans. of Architectural Institute of Japan, No. 104, October, 1964. (in Japanese)
(8) Nakao, M., Experiment on the Behaviour of Steel Beam-to-Column Connections with Large Axial Force of Column, Annual Report of the Engineering Institute Faculty of Engineering, University of Tokyo, Vo1. 32, 1973.

(9) Naka, T., et al., Frame Analysis for Lateral Loading Considering the Shear Distortion of Members, Proc. of the Symposium on Experimental Forces and Structural Design of High Rise and Long Span Structures, Compiled by Japan Society of Civil Engineers and Architectural Institute of Japan, Sept., 1965.

(10) Popov, E.P., Additional Items Affecting Frame Strength, Planning and Design Tall Buildings, Conference Preprints, Discussion-Summary, T6. 16, Stability. 1972

(11) Fielding, D. J., and Chen, W. F. Steel Frame Analysis and Connection Shear Deformation, Proc: of ASCE, Journal of the Structural Division, ST. 1. January, 1973.

(12) ASCE and WRC, Plastic Design in Steel: A Guide and Commentary, The Welding Research Council and the American Society of Civil Engineers, ASCE Manuals and Reports on Engineering Practice No. 41, Second Edition, 1971.

(13) Kato, B., and Nakao, M., The Influence of the Elastic Plastic Deformation of Beam-to-Column Connections on the Stiffness, Ductility and strength of Open Frames, 5th World Conference on Earthquake Engineering, July, 1973, Rome, Italy.

(14) Kato, B., and Morita, K., Transitional Mode of Fracture of Heavy Structural Steel Members, Trans. Architectural Institute of Japan, No. 156, February, 1969. (in Japanese)

(15) Naka, T., et al., Behaviour of Beam-toColumn joint panels subjected to Horizontal Loads (No. 2), Trans. of Architectural Institute of Japan, No. 102, September, 1964. (in Japanese) 
19

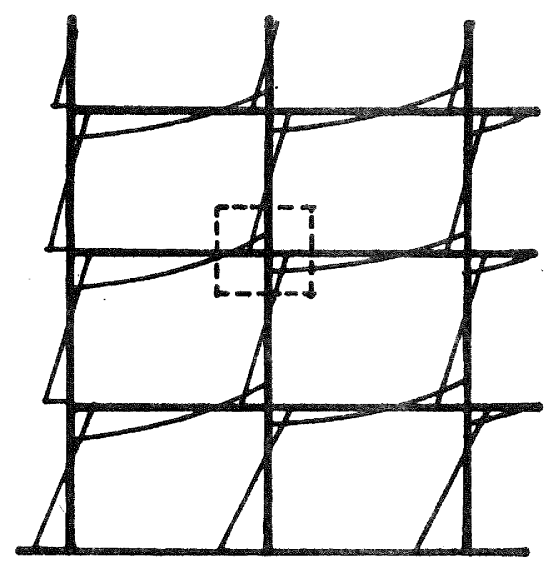

(a)

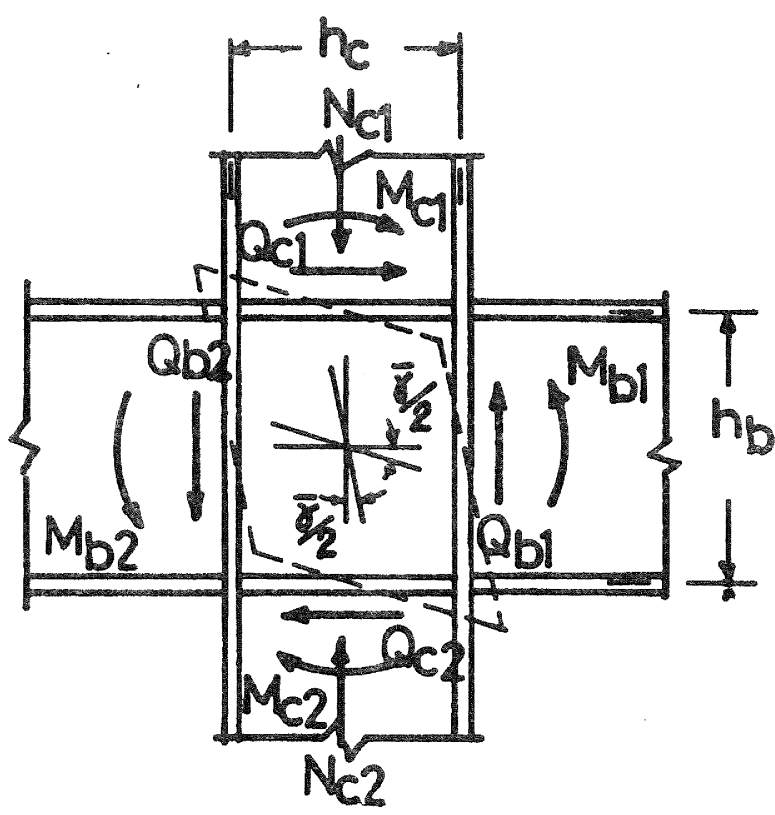

(b)

FIGURE 1: FORCES ACTING ON JOINT PANEL

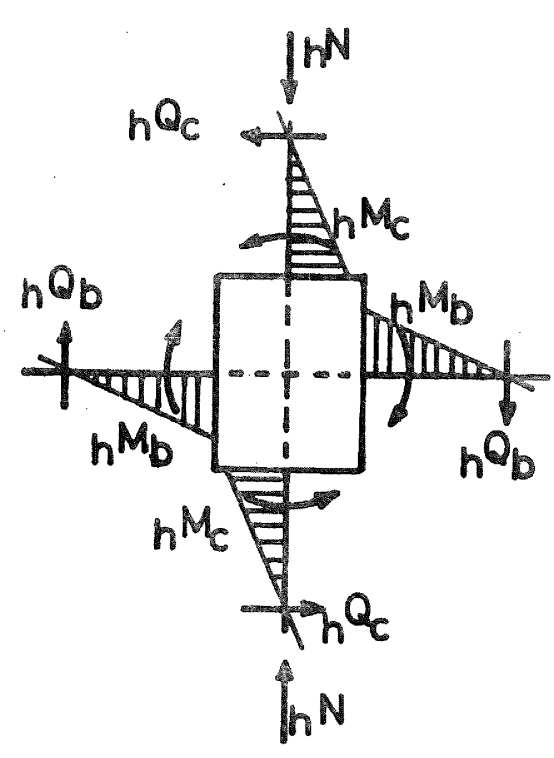

HORIZONTAL LOAD TYPE

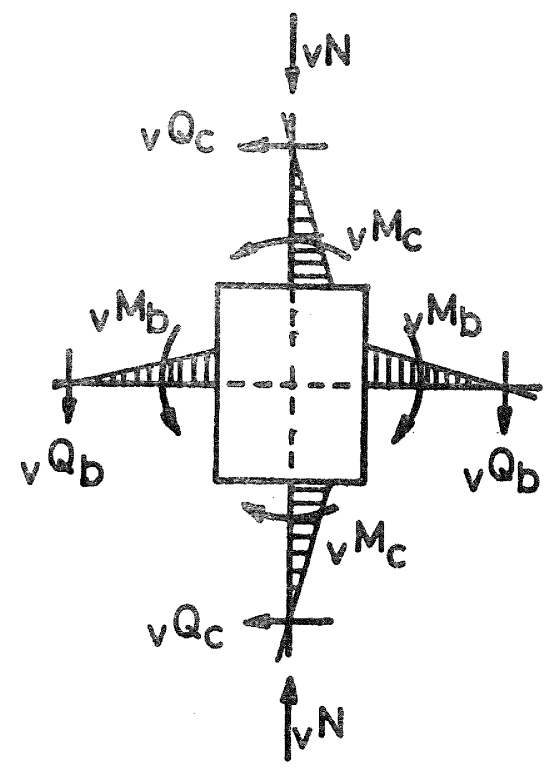

GRAVITY LOAD TYPE

FIGURE 2: LOAD TYPES 


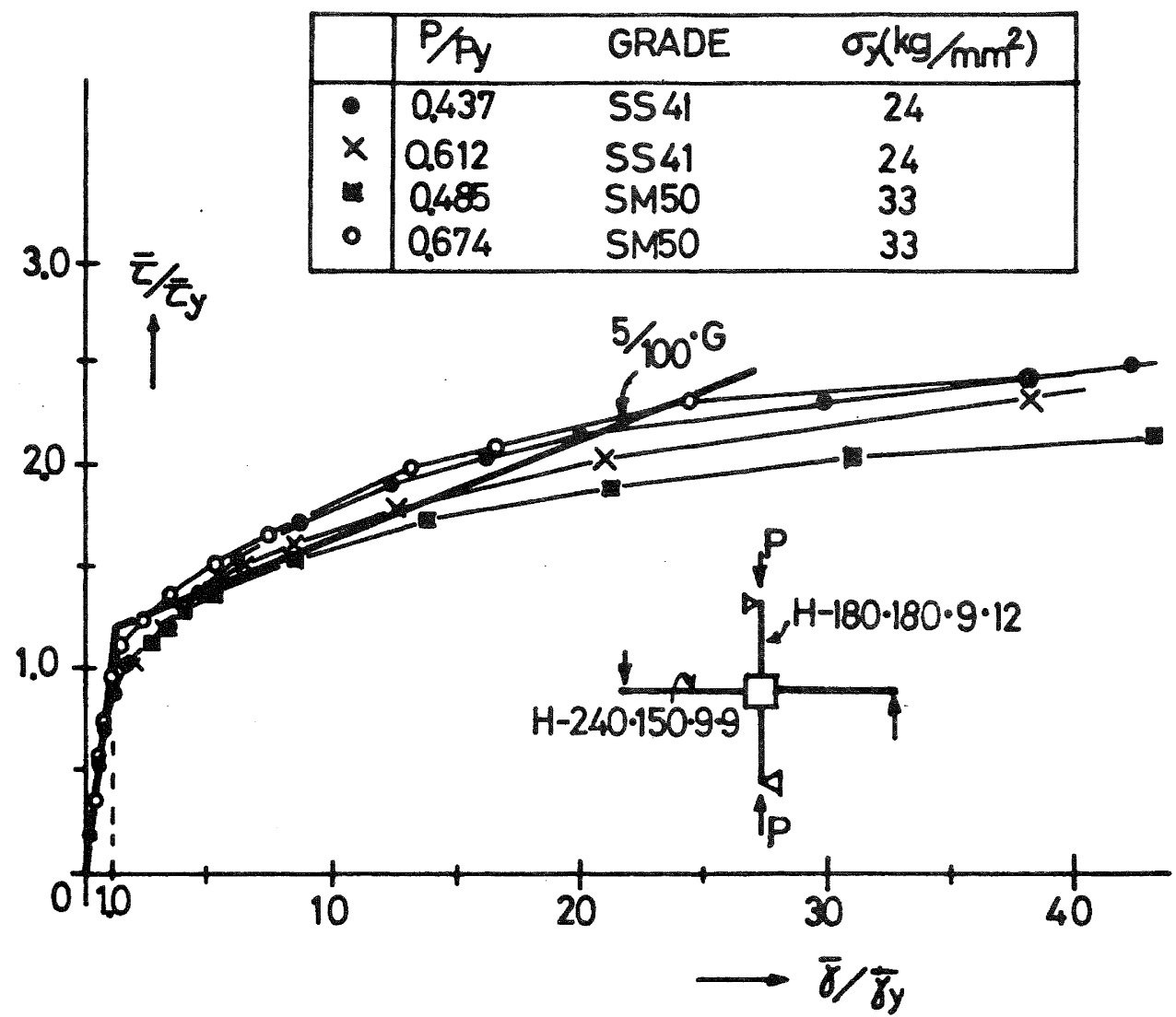

FIGURE 3: $\bar{\tau}-\bar{\gamma}$ RELATION

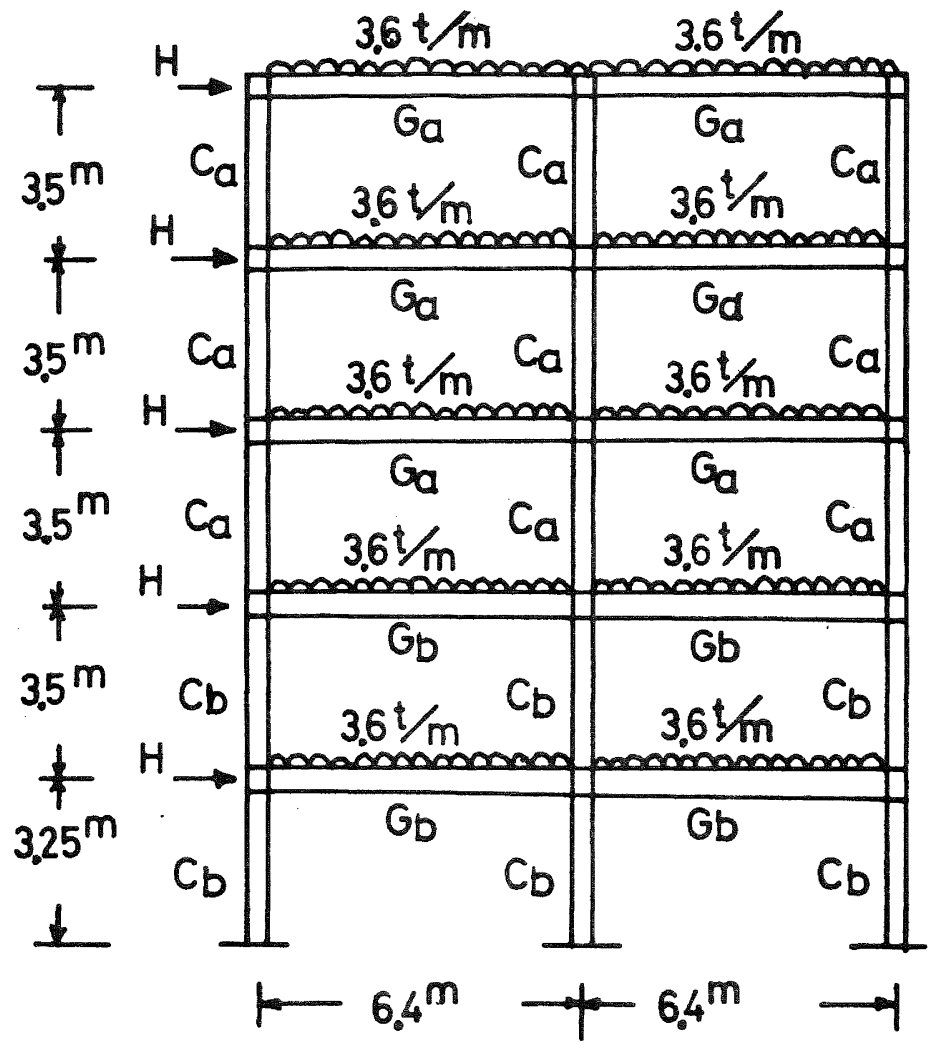

$G_{a}: H 488 \cdot 300 \cdot 11 \cdot 13 \quad G_{b}: H-500 \cdot 200 \cdot 10 \cdot 16$

$C_{a}: H-390 \cdot 300 \cdot 10 \cdot 16 \quad C_{b}: H-400 \cdot 400 \cdot 13 \cdot 21$ 


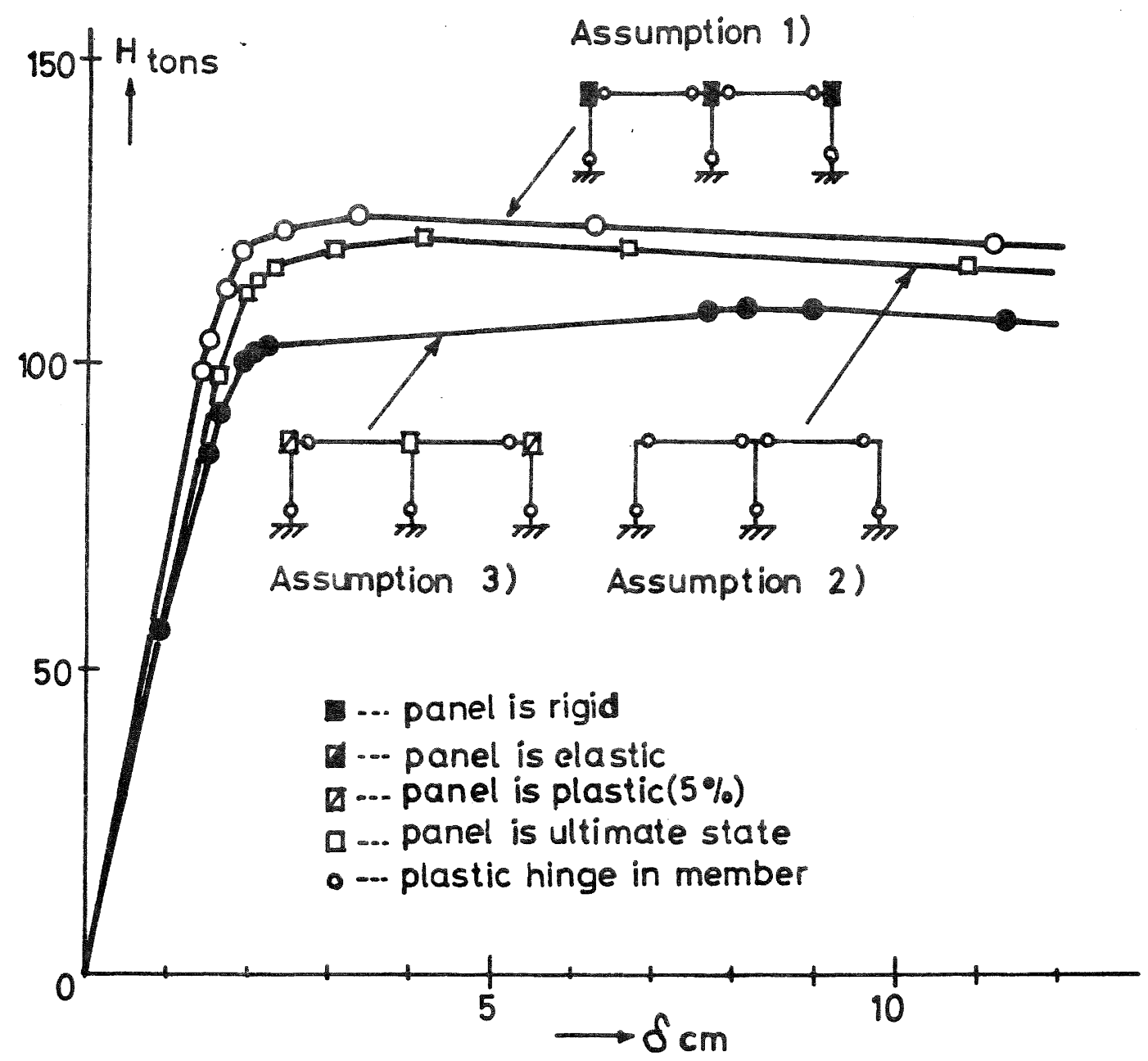

FIGURE 5: FIRST STORY, SHEAR-DRIFT CURVE

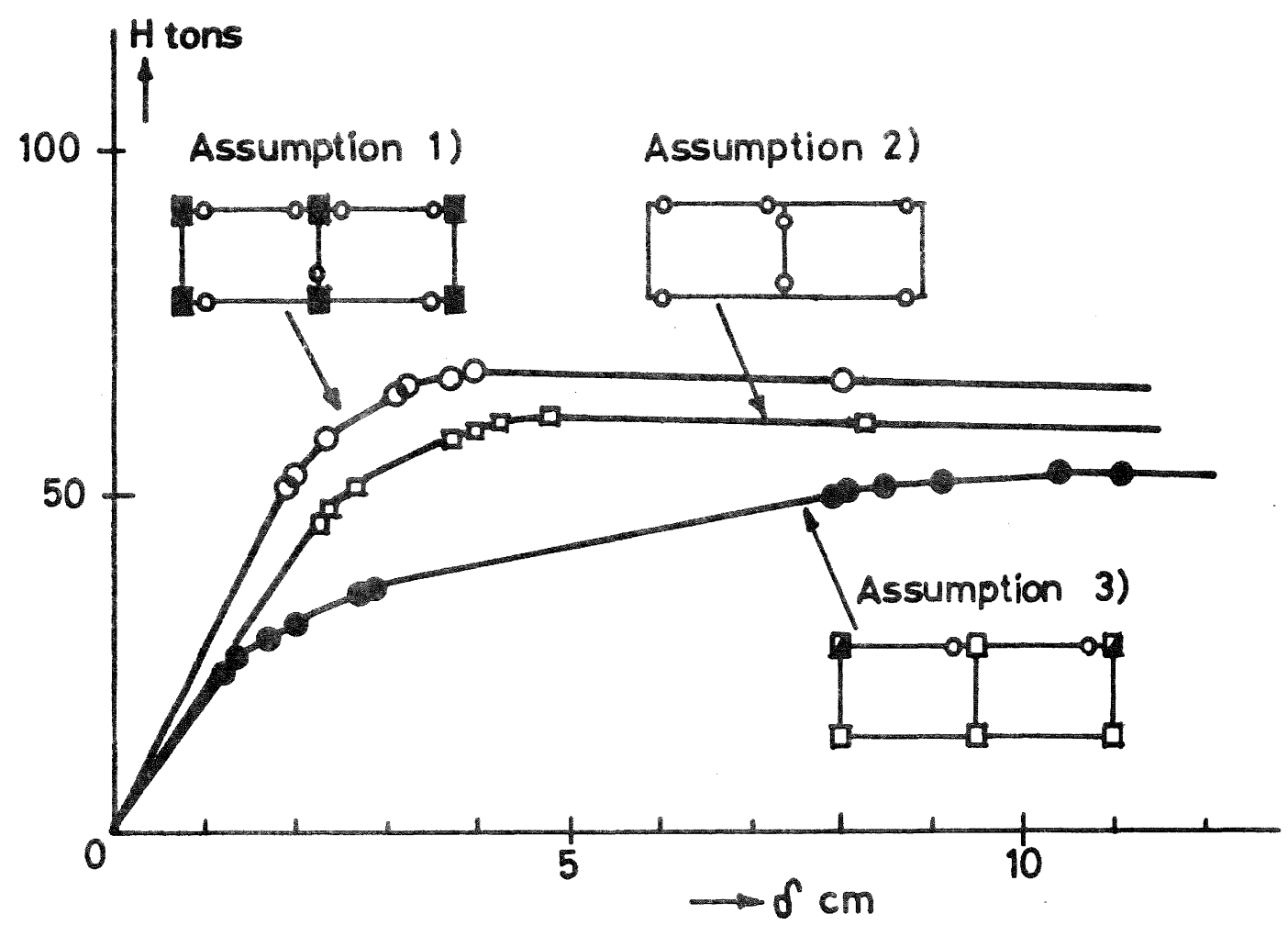

FIGURE 6: THIRD STORY, SHEAR-DRIFT CURVE 


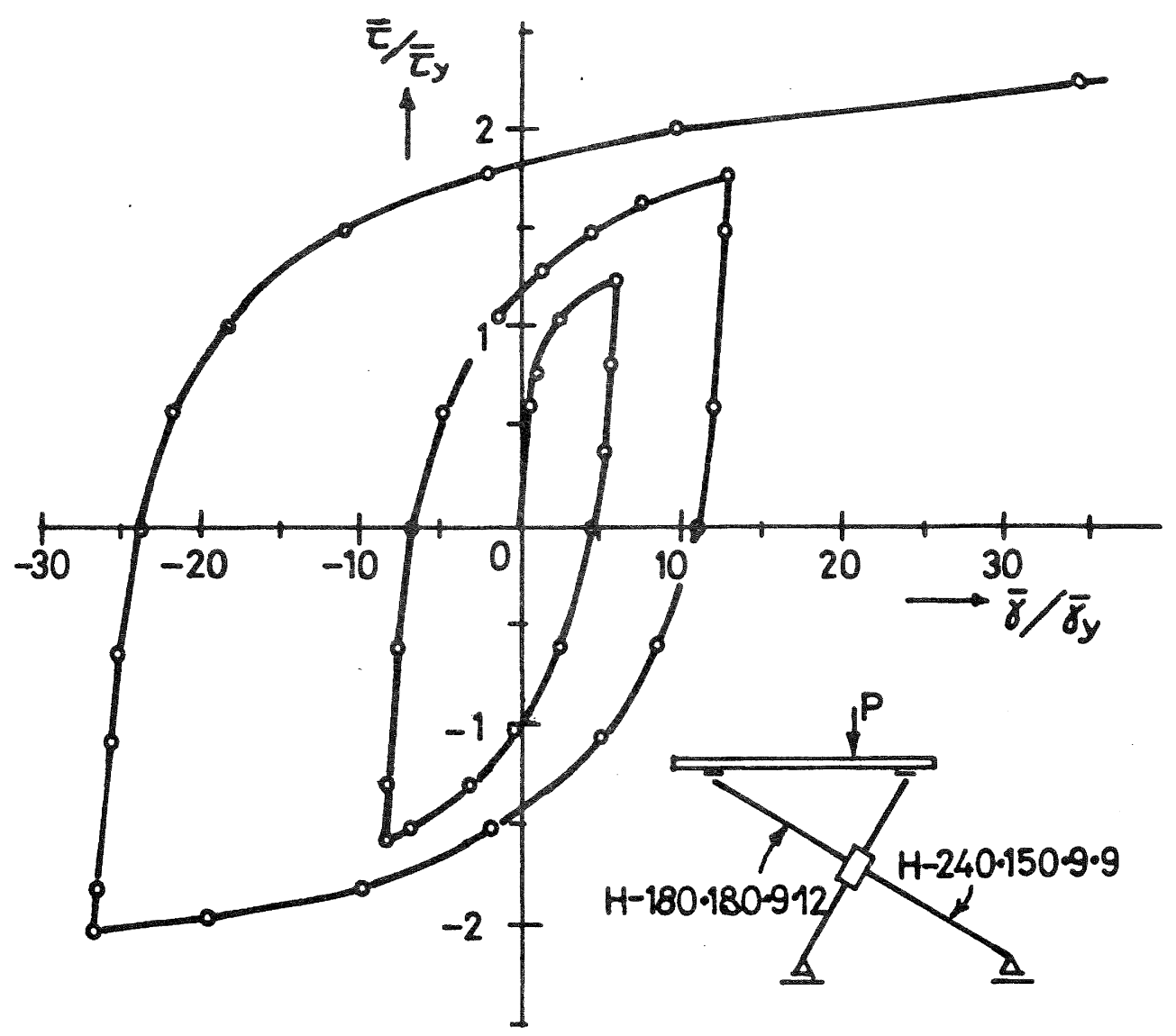

FIGURE 7: CYCLIC BEHAVIOUR
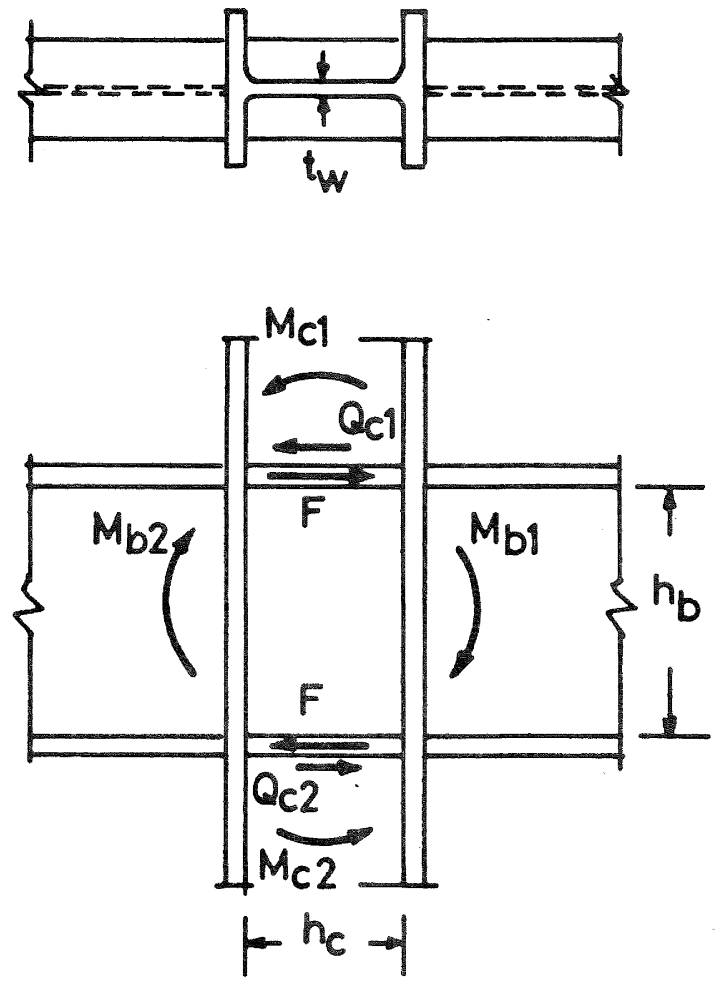

FIGURE 8: H SHAPE JOINT PANEL 


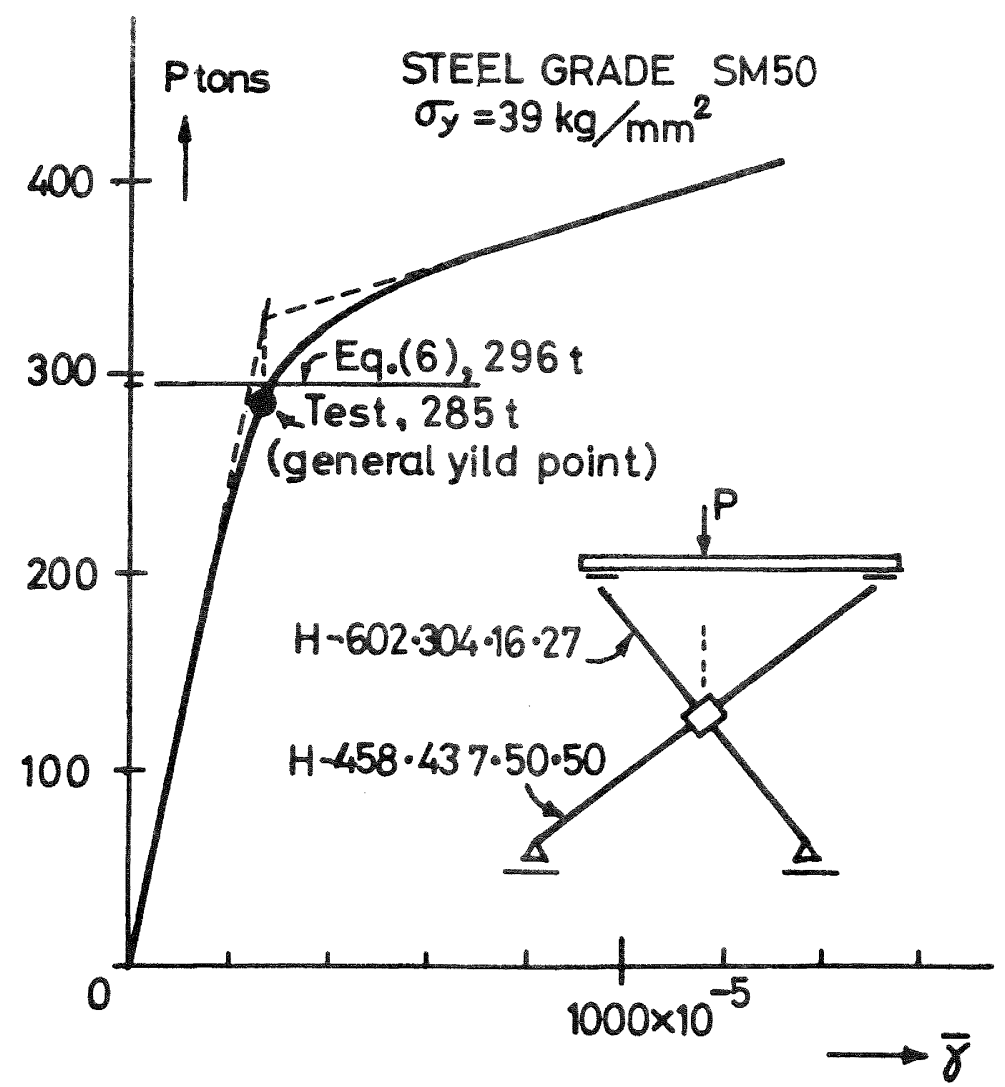

FIGURE 9: TEST RESULT, H SHAPE JOINT PANEL
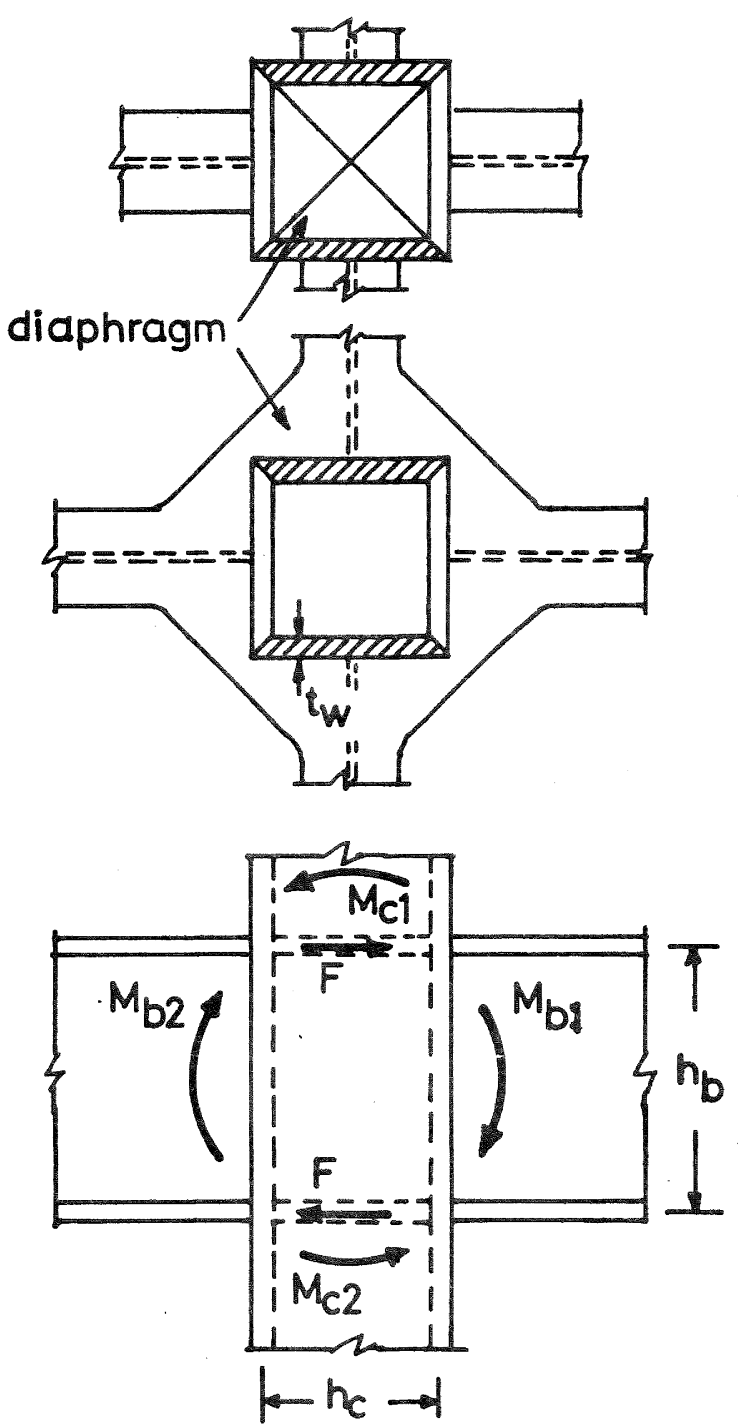

FIGURE 10: BOX SHAPE JOINT PANEL 


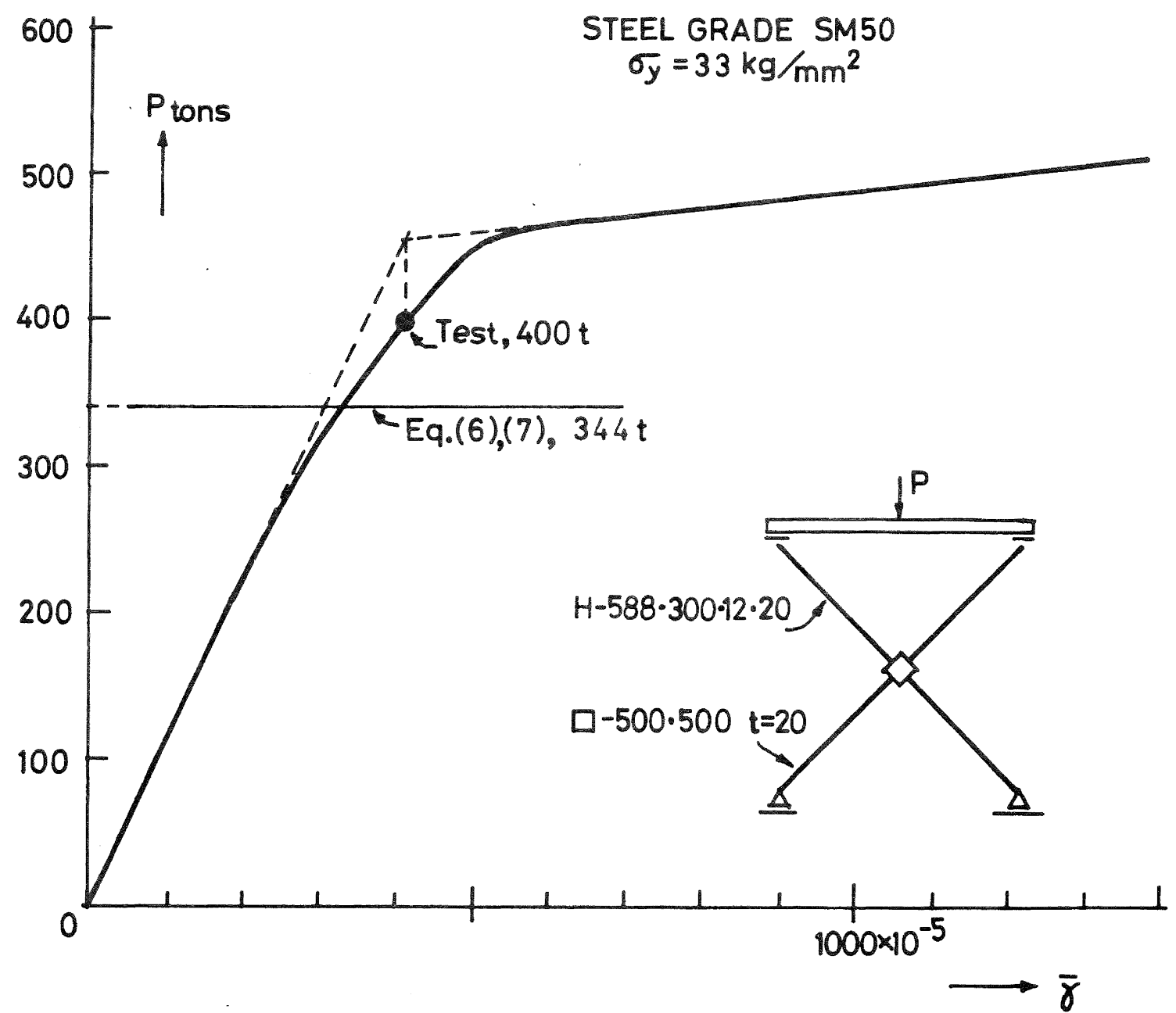

FIGURE 11: TEST RESULT, BOX SHAPE JOINT PANEL
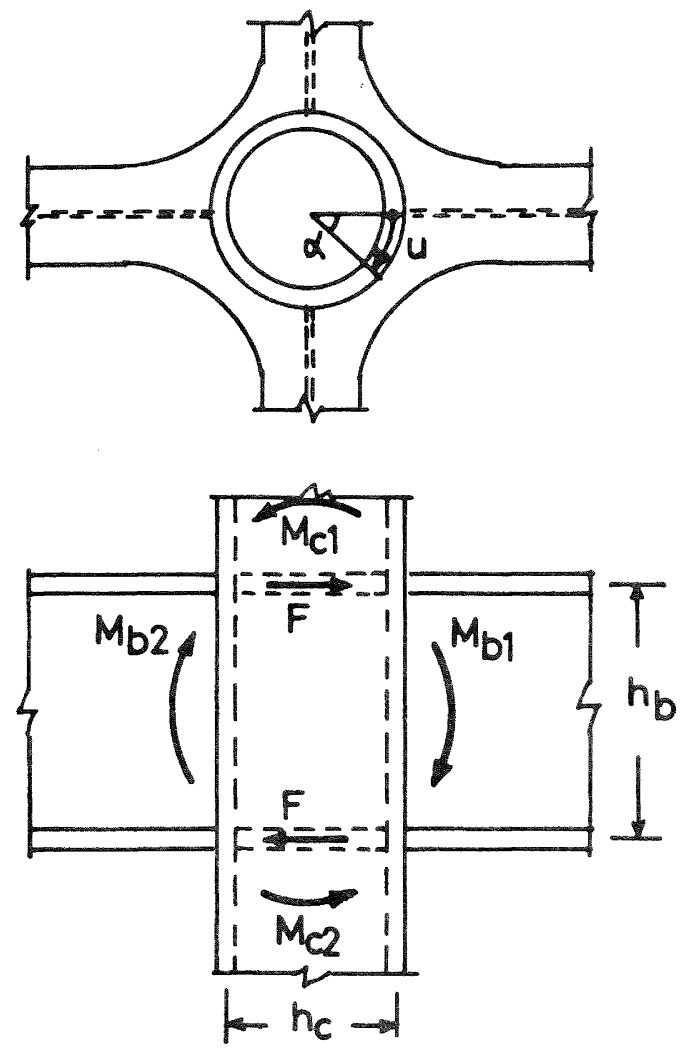

FIGURE 12: TUBULAR JOINT PANEL 


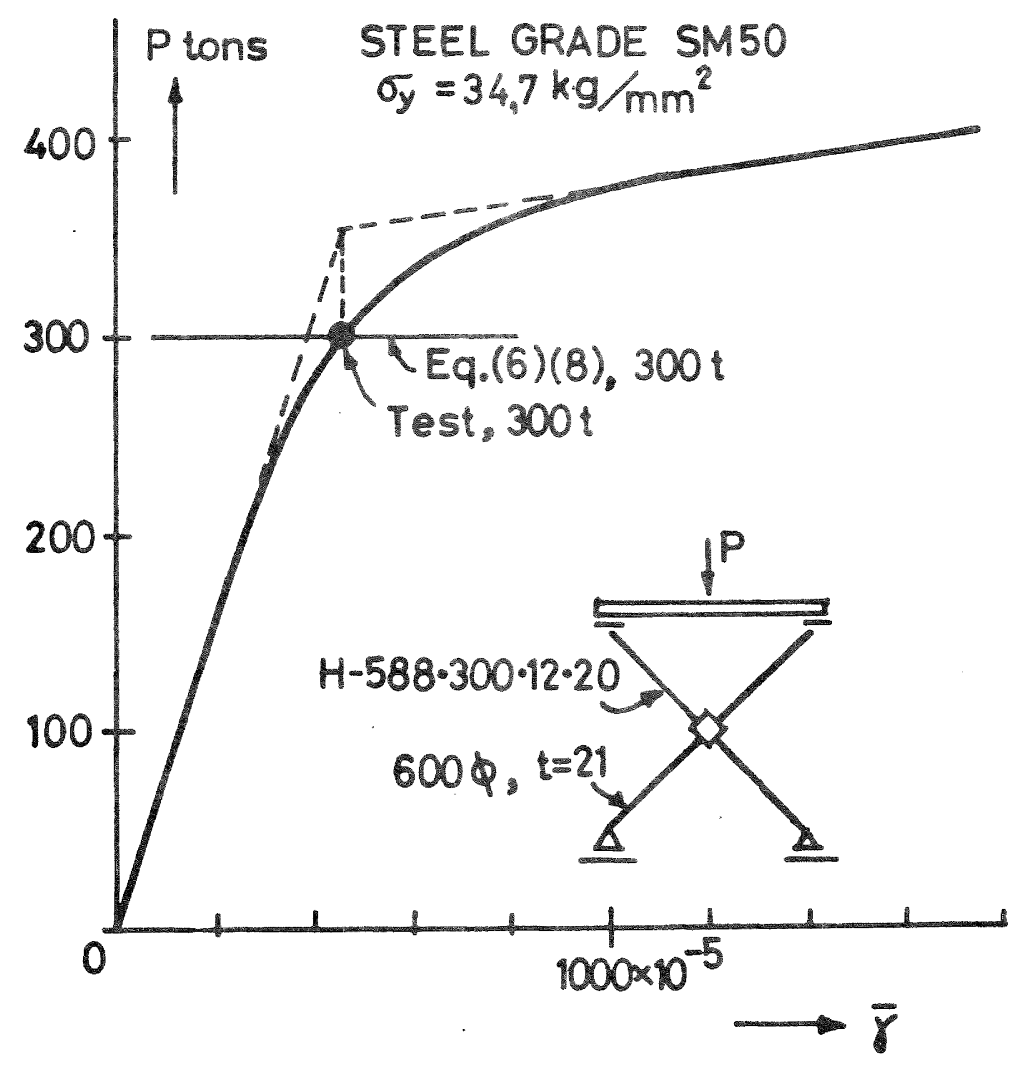

FIGURE 13: TEST RESULT, TUBULAR JOINT PANEL
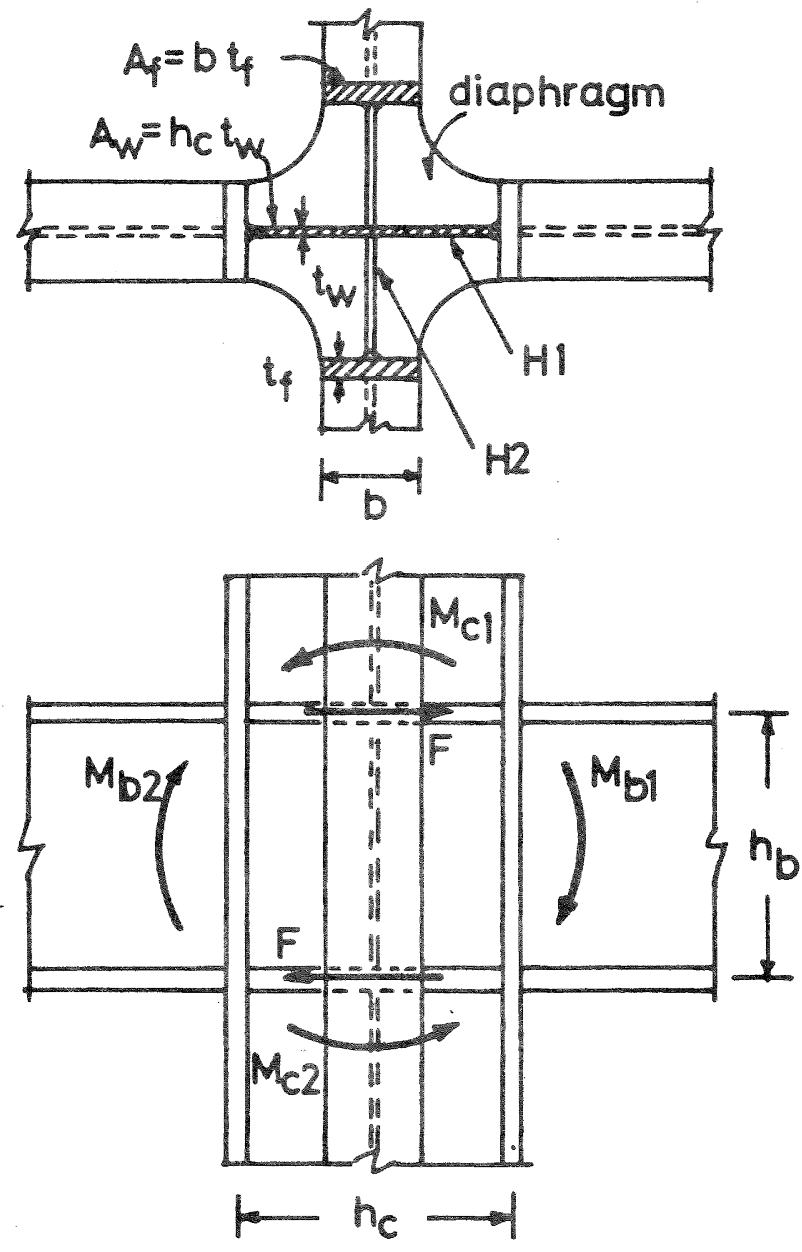

FIGURE 14: ' CROSS-H JOINT PANEL 


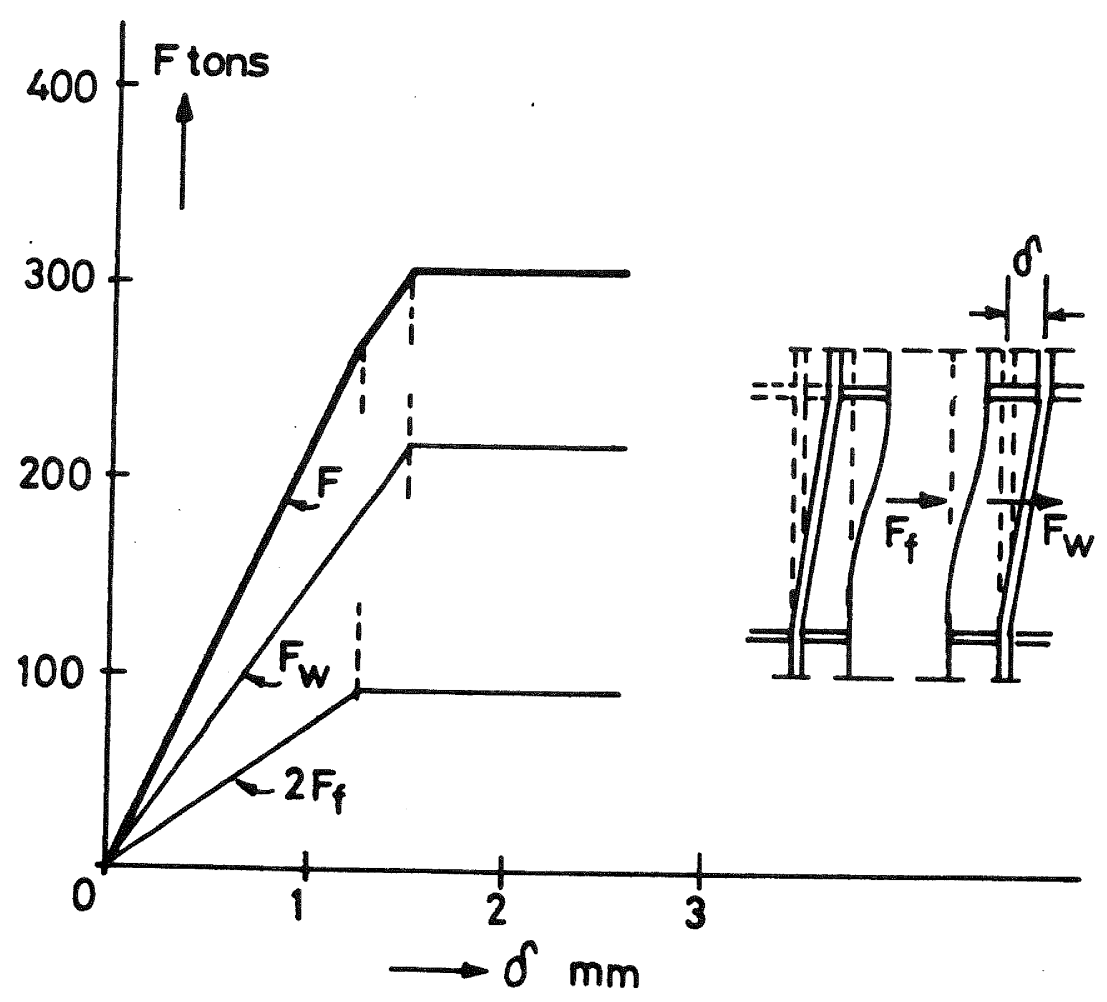

FIGURE 15: DEFORMATION OF CROSS-H PANEL

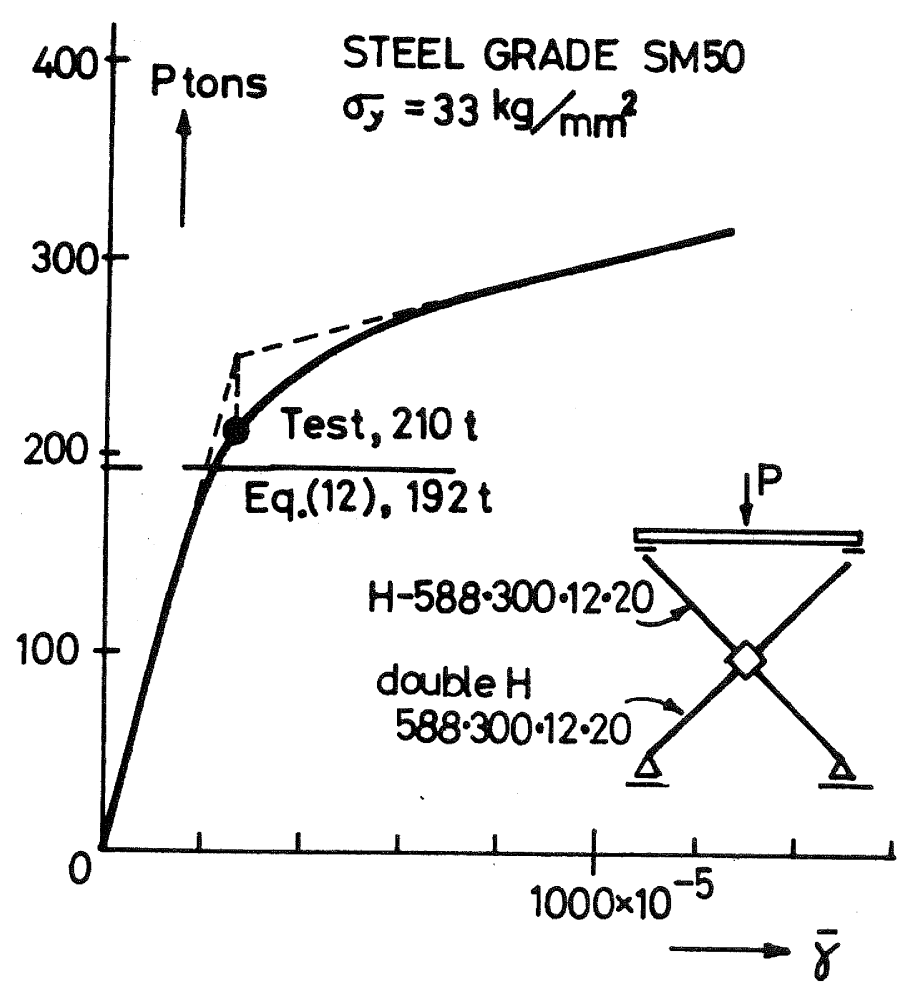

FIGURE 16: TEST RESULT, CROSS-H JOINT PANEL 